\title{
Intussusception in the Syrian Golden hamster
}

\author{
BY STEPHEN C. CUNNANE \\ Department of Nutritional Sciences, Faculty of Medicine, University of Toronto, Toronto, Ontario, \\ M5S 1A8, Canada \\ AND STEPHEN R. BLOOM \\ Royal Postgraduate Medical School, Hammersmith Hospital, DuCane Road, London W12 OHS
}

(Received 19 June 1989 - Accepted 13 October 1989)

\begin{abstract}
Of a series of ninety-six young male Syrian Golden hamsters, $13 \%$ developed lethargy, anorexia, diarrhoea and colocolic intussusception when their diet was changed from a basal laboratory-grade rodent chow to a nutritionally complete semi-purified diet. Histologically, the colon of the hamsters with intussusception had markedly reduced mucus production. Plasma levels of gastric inhibitory polypeptide (GIP) were reduced $80 \%(P<0.01)$ but peptide tyrosine/tyrosine and enteroglucagon in plasma were increased 290 and $526 \%$ respectively in hamsters with intussusception. Variations in dietary fatty acid composition had no effect but intussusception was not observed after changing the dietary carbohydrate from sucrose to starch.
\end{abstract}

Colon: Cystic fibrosis: Intussusception: Peptide hormones: Hamster

Intussusception (IN) is a relatively uncommon acute condition in which a proximal portion of intestine (intussusceptum) telescopes or invaginates into an adjacent distal portion (intussuscipiens). The location is most frequently ileo-ileal or ileo-colic. IN is usually found without related illness and its etiology is not understood. In children, IN is most commonly considered to be induced by viral illness in which mesenteric lymph nodes may become inflamed and act as a lead point for the IN (Anon, 1985). In adults, intestinal polyps, inverted Meckel's diverticulum or tumours may initiate an IN. Diet is rarely considered to be a significant factor. IN is, nevertheless, most commonly reported in children with cystic fibrosis, a disease manifested by chronic malnutrition (Park \& Grand, 1981).

Domesticated animals have also been reported to get spontaneous IN (Weaver, 1985). In a recently reported study of dogs with IN, the location was primarily jejunal or ileo-colic. Pain, vomiting and diarrhoea were the dominant symptoms. Intestinal prolapse through the anus was also observed. As in humans, the etiology was obscure, although a change of diet was considered to be relevant, particularly if the IN occurred in the early post-weaning period (Weaver, 1985).

The present paper reports the occurrence of spontaneous IN in young, male Syrian Golden hamsters. Its onset was related to a change in diet from the standard laboratory chow (basal diet) to a semi-purified diet containing $650 \mathrm{~g}$ sucrose $/ \mathrm{kg}$. Since altered gut motility may be a factor in the development of IN and since gut peptide hormones modulate gut motility, plasma levels of gut peptides were measured.

\section{METHODS}

Animals and diets

The animals used throughout the present study were 4-week-old $(50-60 \mathrm{~g})$ male Syrian Golden hamsters obtained from Canadian Hybrid Farms (Halls Harbour, Nova Scotia). 
Table 1. Incidence of intussusception (IN) in male Syrian Golden hamsters fed on semipurified diets varying in fat and carbohydrate content

\begin{tabular}{|c|c|c|c|c|c|c|}
\hline \multirow[b]{3}{*}{ Diet } & \multicolumn{4}{|c|}{ Diet } & \multirow[b]{3}{*}{ IN : total } & \multirow{3}{*}{$\begin{array}{l}\text { Percentage } \\
\text { of total }\end{array}$} \\
\hline & \multicolumn{2}{|c|}{ Fat } & \multicolumn{2}{|c|}{ Carbohydrate } & & \\
\hline & Type & $\mathrm{g} / \mathrm{kg}$ & Type & $\mathrm{g} / \mathrm{kg}$ & & \\
\hline Basal chow & Mixed & 45 & Mixed & 500 & $0: 100+$ & 0 \\
\hline Semi-purified & SFO & 100 & Sucrose & 650 & $4: 25$ & 16 \\
\hline Semi-purified & SBO & 100 & Sucrose & 650 & $2: 18$ & 11 \\
\hline Semi-purified & CLO & 100 & Sucrose & 650 & $4: 23$ & 17 \\
\hline Semi-purified & HBT & 100 & Sucrose & 650 & $2: 20$ & 10 \\
\hline Semi-purified & SFO & 100 & Starch & 650 & $0: 10$ & 0 \\
\hline
\end{tabular}

SFO, safflower oil; SBO, soya-bean oil; CLO, cod-liver oil; HBT, hydrogenated beef tallow.

They were being studied for dietary effects on fatty acid and lipid composition when IN was observed in some but not other groups. This is, therefore, a retrospective description of the occurrence of IN. Ninety-six male animals were studied in total. They were housed in groups of five hamsters each in large polypropylene cages fitted with stainless-steel wiregrid tops (Nalgene; Fisher Scientific, Dartmouth, Nova Scotia). Pelleted laboratory rodent chow (no. 5001, Purina, St Louis, MO, USA) and tap water were available ad lib.

The hamsters in the initial study in which IN was observed were destined for an experiment involving manipulation of dietary fatty acid composition. In order to feed the hamsters a diet of defined fatty acid composition, semi-purified diets were prepared in which essential nutrients were present at concentrations recommended for hamsters (American Institute of Nutrition, 1977). The major dietary components (casein, mineral mix and vitamin mix) were obtained from Teklad Test Diets (Madison, WI, USA). The diet formula was $(\mathrm{g} / \mathrm{kg}): 655$ sucrose, 20 casein, 10 fat, 3.5 minerals (American Institute of Nutrition, no. 76), 1 vitamin mix (American Institute of Nutrition, no. 76A). The fat source was soya-bean oil ( $50 \%$ linoleic acid, $15 \% \alpha$-linolenic acid), safflower oil ( $78 \%$ linoleic acid), cod-liver oil ( $8 \%$ eicosapentaenoic acid, $8 \%$ docosahexaenoic acid) or hydrogenated beef tallow ( $29 \%$ palmitic acid, $60 \%$ stearic acid).

Once it became apparent that changing the hamsters from the basal chow to the semipurified diet might have precipitated the IN, the dietary components responsible were investigated. Various fat sources had been used in the diets of the previous series of hamsters but IN occurred in a similar proportion from each group (Table 1). Since the diet contained $655 \mathrm{~g}$ sucrose $/ \mathrm{kg}$ (an amount well-tolerated by the rat for which the diet is also prepared), intolerance to simple sugars was considered a possibility. Accordingly, a group of male hamsters was given the semi-purified diet with maize starch replacing sucrose.

\section{Histology}

Sections of colon and pancreas from healthy, chow-fed hamsters and from hamsters with IN were dissected, fixed in formalin and prepared for light microscopy by standard techniques. Colon samples were sectioned proximal to and within the IN.

\section{Peptide hormones}

Plasma from hamsters with fully developed IN (e.g. Plates 1 and 2) was assayed for gut peptide hormones. Controls for these assays were healthy chow-fed hamsters. Gastrin, gastric inhibitory polypeptide (GIP), peptide tyrosine/tyrosine (PYY), enteroglucagon, 
Table 2. Organ weights in young male Syrian Golden hamsters which developed intussusception while being fed on a semi-purified diet $\dagger$

(Means and standard deviations for six animals/group)

\begin{tabular}{|c|c|c|c|c|}
\hline & \multicolumn{2}{|c|}{ Control } & \multicolumn{2}{|c|}{ Intussusception } \\
\hline & Mean & SD & Mean & SD \\
\hline Liver (g) & $4 \cdot 78$ & 0.43 & $1.67^{* * *}$ & $0 \cdot 29$ \\
\hline Pancreas (mg) & 147 & 13 & $80^{* *}$ & 13 \\
\hline Gall bladder $(\mathrm{mg})$ & 16 & 6 & $68 * *$ & 39 \\
\hline
\end{tabular}

Mean values were significantly different from control values (Student's $t$ test): ${ }^{* *} P<0.01$.

$\dagger$ For details, see p. 232.

motilin, neurotensin and pancreatic polypeptide were measured by radioimmunoassay as previously described in detail (Bloom \& Polak, 1981). Antibodies were raised to, and standards used from peptides of the following species: gastrin and pancreatic polypeptide (human); GIP, PYY, motilin and neurotensin (porcine).

\section{Statistics}

Student's $t$ test was used for statistical comparisons between the two groups.

\section{RESULTS}

\section{General description}

Within $10 \mathrm{~d}$ of having been changed from the basal chow diet to the new semi-purified diet, twelve of the twenty hamsters in the initial study had become anorectic and nine developed watery diarrhoea (commonly known as 'wet-tail' in hamsters). Four of these hamsters developed IN within $48 \mathrm{~h}$ (three diagnosed at necroscopy and one presented with anally prolapsed IN). All four cases of IN involved exclusively the colon (colo-colic).

The typical gross presentation is shown in Plate 1. The terminal ileum, caecum, colon and rectum were dissected from this animal and are shown adjacent to a similar segment of gastrointestinal tract from a healthy chow-fed hamster (Plate 2). The almost complete invagination of the colon into the rectum resulted in an $18 \mathrm{~mm}$ prolapse of the colon (not the rectum). The diet was not initially perceived of as relevant to the occurrence of IN in these hamsters so further studies were carried out (each initially with a different purpose). A total of twelve of ninety-six (13\%) male Syrian Golden hamsters developed IN (Table 1). Ten cases were colo-colic, one was duodeno-duodenal and one was caeco-colic. Associated symptoms were anorexia, lethargy, weight loss, gall bladder distension, steatorrhoea, diarrhoea, ileal-caecal haemorrhage and ileal-caecal spasm.

Organ weights in one series of healthy chow-fed hamsters were compared with those of hamsters of the same age and starting weight which developed IN after having been fed on the semi-purified diet for 10-14 d. In the hamsters with IN, liver and pancreas weights were significantly reduced but gall bladders were grossly distended with bile (Table 2).

\section{Histology}

A cross-section of the colon of a normal healthy hamster was compared with a section of colon immediately proximal to an IN and through an IN (Plate 3). The predominant features of the sections from the animal with IN which were different from the healthy hamster were: (1) reduced mucus in the intestinal crypts, (2) the reduction in the depth of 
Table 3. Plasma levels (pmol/l) of gut peptide hormones in young male Syrian Golden hamsters with intussusception

(Means and standard deviations for four animals/group)

\begin{tabular}{|c|c|c|c|c|}
\hline & \multicolumn{2}{|c|}{ Control } & \multicolumn{2}{|c|}{ Intussusception } \\
\hline & Mean & SD & Mean & SD \\
\hline Gastrin & $10 \cdot 8$ & $4 \cdot 7$ & 6.9 & $5 \cdot 0$ \\
\hline Gastric inhibitory polypeptide & $24 \cdot 5$ & $7 \cdot 3$ & $5 \cdot 1 * *$ & $2 \cdot 7$ \\
\hline Peptide tyrosine/tyrosine & $38 \cdot 2$ & $12 \cdot 6$ & $109 \cdot 6^{*}$ & $64 \cdot 3$ \\
\hline Enteroglucagon & $99 \cdot 5$ & $31 \cdot 3$ & $523 \cdot 5^{*}$ & $354 \cdot 2$ \\
\hline
\end{tabular}

Mean values were significantly different from control values (Student's $t$ test): ${ }^{*} P<0 \cdot 05,{ }^{* *} P<0 \cdot 01$.

the muscularis mucosae, (3) the infiltration by polymorphonuclear leucocytes. The marked reduction in mucus in the mucosal crypts of the hamsters with IN is shown in Plate 4. Pancreas sections were similar in the two groups (controls and IN) but accumulation of zymogen granules appeared to be greater in those with IN (not shown).

\section{Gut peptide hormones}

Plasma values of gut peptide hormones are shown in Table 3. Motilin, pancreatic polypeptide and neurotensin were undetectable in both controls and hamsters with IN, presumably due to species differences between porcine and hamster peptide sequences. Gastrin did not differ significantly between groups. In the hamsters with IN, GIP was $80 \%$ lower $(P<0.01)$, but PYY was 2.9 times higher $(P<0.05)$ and enteroglucagon was 5.3 times higher $(P<0 \cdot 01)$ than in the controls.

\section{Faecal fat content}

Faecal fat was measured over a $5 \mathrm{~d}$ period in fifteen male hamsters given the purified diet. Ten hamsters developed diarrhoea and died. They had $20 \%$ higher faecal fat output than those remaining healthy (an increase of 1.5 (SD 1.1) $\mathrm{g}$ fat in the faeces over the $5 \mathrm{~d}$ period, $P<0.01$ ). Of the hamsters with diarrhoea one developed IN (after $2 \mathrm{~d}$ on the diet); it had an increase in faecal fat of $0.8 \mathrm{~g}(15 \%)$ over the $2 \mathrm{~d}$. The five remaining hamsters were healthy and were killed on day 5 . They had no significant change in faecal fat over the $5 \mathrm{~d}$ period.

\section{DISCUSSION}

We have presented evidence that spontaneous IN occurs in the young male Syrian Golden hamster fed on a semi-purified nutritionally adequate diet. The location was primarily colocolic, and anal prolapse of the intussuscepted colon was observed in some cases. Once the hamsters started on the semi-purified diet, IN developed rapidly (within 7-10 d). The etiology appears to be related to a change from a basal diet (rodent chow) made from unrefined foods to a semi-purified diet made from highly refined foods. Intercurrent viral gastroenteritis with associated diarrhoea may have been present in some or all of these hamsters, and may have been a predisposing cause of IN. However, since IN has not been observed in any of our previous studies with hamsters of the same age from the same supplier when fed on rodent chow, an effect of a change in diet must have precipitated IN in these animals.

Transmissible ileal hyperplasia in hamsters has many of the symptoms also observed in the present study, including anorexia, lethargy, weight loss and diarrhoea (Jacoby, 1985). 
However, the ileal hyperplasia is readily visible macroscopically and, to our knowledge, was not a visible feature of the hamsters in the present study, nor was it evident by light microscopy. Unfortunately, we did not do any electron microscopy, nor were any bacterial assessments done which would have clearly identified the cause of IN. The absence of IN in hamsters not fed on the sucrose-rich semi-synthetic diet strongly suggests that bacterial or viral infestation in these hamsters was not sufficient alone to precipitate IN without the change in diet.

The chow diet (which was not associated with IN) contained $230 \mathrm{~g}$ protein $/ \mathrm{kg}$ from various sources including fish, lucerne (Medicago sativa) and grains, $45 \mathrm{~g}$ fat $/ \mathrm{kg}$ from mixed plant and animal sources, recommended amounts of minerals and vitamins and natural plant fibre and complex carbohydrates. The semi-purified diet (which was associated with all cases of IN) was based on $(\mathrm{g} / \mathrm{kg})$ : 650 sucrose, 200 casein, 100 fat and recommended amounts of minerals and vitamins. It lacked complex carbohydrates. The fat used was from plant origin (safflower or soya-bean oils), marine origin (cod-liver oil) or animal origin (hydrogenated beef tallow). The incidence of IN was comparable regardless of fat source (Table 1) but was reduced to $0 \%(n 10)$ when the carbohydrate source was changed from sucrose to maize starch.

Excess dietary sucrose could have caused water to be osmotically retained by the colon and could, therefore, be a causative factor in the diarrhoea which generally preceded the onset of IN. In the hamsters with IN, colonic mucus production at the time of IN was less than in the controls (Plate 3). This could have facilitated the adherence of a faecal bolus in a colon with poor motility and, thus, become the apex of the intussusceptum. Reduced bile secretion was apparent in the hamsters with IN from the grossly distended gall bladders. This would reduce fat digestion, contribute to slower intestinal transit time (Spiller et al. 1984), and perhaps account for the 15-20\% increase in faecal fat in the hamsters with diarrhoea or IN, or both. Rings of tightly contracted colon in apparent spasm were also observed in some hamsters with IN and in others with diarrhoea.

Analysis of gut peptide hormones was undertaken to further evaluate intestinal motility in the hamsters with IN. Unfortunately, although analysis of the peptides in situ in the colon and pancreas was attempted, it was unsuccessful because of cross-species differences between the hamster peptides and the rat antibodies used in the assay. Plasma levels of four of the gut peptides were detectable (gastrin, GIP, PYY and enteroglucagon). Of these, GIP was significantly reduced but PYY and enteroglucagon were increased in the hamsters with IN (Table 3). The relevance of a drop in plasma GIP is unknown as its main role is considered to be in the release of insulin during hyperglycaemia. PYY, however, is secreted from the mucosal endocrine cells of the ileum and colon (Bloom \& Polak, 1981) and is known to slow down intestinal transit time. PYY has also been shown to be elevated in conditions of malabsorption (S. R. Bloom, unpublished results). The 2.9-fold increase in plasma levels of PYY in hamsters with IN (Table 4) may, therefore, have a direct bearing on IN. Enteroglucagon is important for the maintenance of normal intestinal mucosal growth (Bloom, 1972) and is present maximally in the ileum and colon (Miazza et al. 1985). In humans, acute diarrhoea (Bryant et al. 1983) and increased content of fat (Spiller et al. 1984) are associated with increased plasma enteroglucagon. Both were present in the hamsters with IN.

If there is any clinical relevance of this hamster model of IN, it may be in relation to cystic fibrosis. Symptoms seen in cystic fibrosis which were also present in the hamsters fed on the sucrose-rich semi-purified diet include a relatively high incidence of IN $(1-5 \%)$ and cholestasis. In addition, plasma levels of GIP have been reported to be low (Allen et al. 1983), whereas enteroglucagon is increased fourfold (Adrian et al. 1980) in cystic fibrosis. These peptide-hormone changes in cystic fibrosis are consistent with those seen in the 
present hamsters with IN (Table 3). The present model of IN in the hamster suggests that in cystic fibrosis, proportionally high intake of simple carbohydrates may facilitate the occurrence of IN.

The potential role of diet has been alluded to as a causative factor in canine IN (Weaver, 1985). In the light of our present findings, and the fact that in the majority of cases IN has no known cause (Strang, 1959), diet may be an important factor in human IN.

S.C.C. thanks the Natural Sciences and Engineering Research Council of Canada for continued financial support, the Efamol Research Institute, Kentville, Nova Scotia, for technical facilities and assistance, and the Blanchard Fraser Memorial Hospital, Kentville, Nova Scotia for histology.

\section{REFERENCES}

Adrian, T. E., McKeirnan, J., Johnstone, D. I., Hiller, E. J., Vyes, H., Sarson, D. L. \& Bloom, S. R. (1980). Hormonal abnormalities of the pancreas and gut in cystic fibrosis. Gastroenterology 79, 460-465

Allen, J., Penketh, A. R. L., Adrian, T. E., Lee, Y. C., Sarson, D. L., Hodson, M. E., Batten, J. C. \& Bloom, S. R. (1983). Adult cystic fibrosis: postprandial response of gut regulatory peptides. Gastroenterology 85, $1379-1383$.

American Institute of Nutrition (1977). Report of the AIN ad hoc committee on standards for nutrition studies. Journal of Nutrition 107, 1340-1348.

Anon (1985). Acute intussusception in children. Lancet ii, 250-251.

Bloom, S. R. (1972). An enteroglucagon tumor. Gut 13, 520-523.

Bloom S. R. \& Polak, J. M. [editors] (1981). Hormone profiles. In Gut Hormones, pp. 555-560. Edinburgh: Churchill Livingstone.

Bryant, B. G., Bloom, S. R., Polak, J. M., Hobbs, S., Domschke, W., Domochke, S., Mitznegg, H., Ruppin, H. \& Demling, L. (1983). Measurement of gut hormonal peptides in biopsies from human stomach and proximal small intestine. Gut 24, 114-119.

Jacoby, R. O. (1985). Transmissal ileal hyperplasia, hamster. In Digestive System, pp. 346-355 [T. C. Jones, U. Mohr and R. D. Hunt]. New York: Springer-Verläg.

Handler, A. H. \& Chesterman, F. C. (1968). Spontaneous disease. In The Golden Hamster: Its Biology and Use in Medical Research, pp. 209-214 [R. A. Hoffman, P. F. Robinson and H. Magalhaes, editors]. Ames, Iowa: Iowa State University Press.

Miazza, B. M., Al-Mukhtar, Salmeron, M., Ghatei, M. A., Felce-Dachez, M., Filali, A., Villet, R., Wright, N. A., Bloom, S. R. \& Crambaud, J. P. (1985). Hyperenteroglucagonemia and small intestine mucosal growth after colonic perfusion of glucose in rats. Gut 26, 518-524.

Park, R. W. \& Grand, R. J. (1981). Gastrointestinal manifestations of cystic fibrosis - a review. Gastroenterology 81, 1143-1161.

Spiller, R. C., Lee, Y. C., Edge, C., Ralphs, D. N. L., Bloom, S. R., Stewart, J. C. \& Silk, D. B. A. (1984). Functional significance of the ileal break in celiac disease. Gut 25, A545.

Strang, R. (1959). Intussusception in infancy and childhood - a review. British Journal of Surgery 46, 484 495.

Weaver, A. D. (1985). Canine intestinal intussusception. In Animal Models for Intestinal Disease, pp, 205-214 [C. J. Pfeiffer, editor]. Boca Raton: CRC Press. 


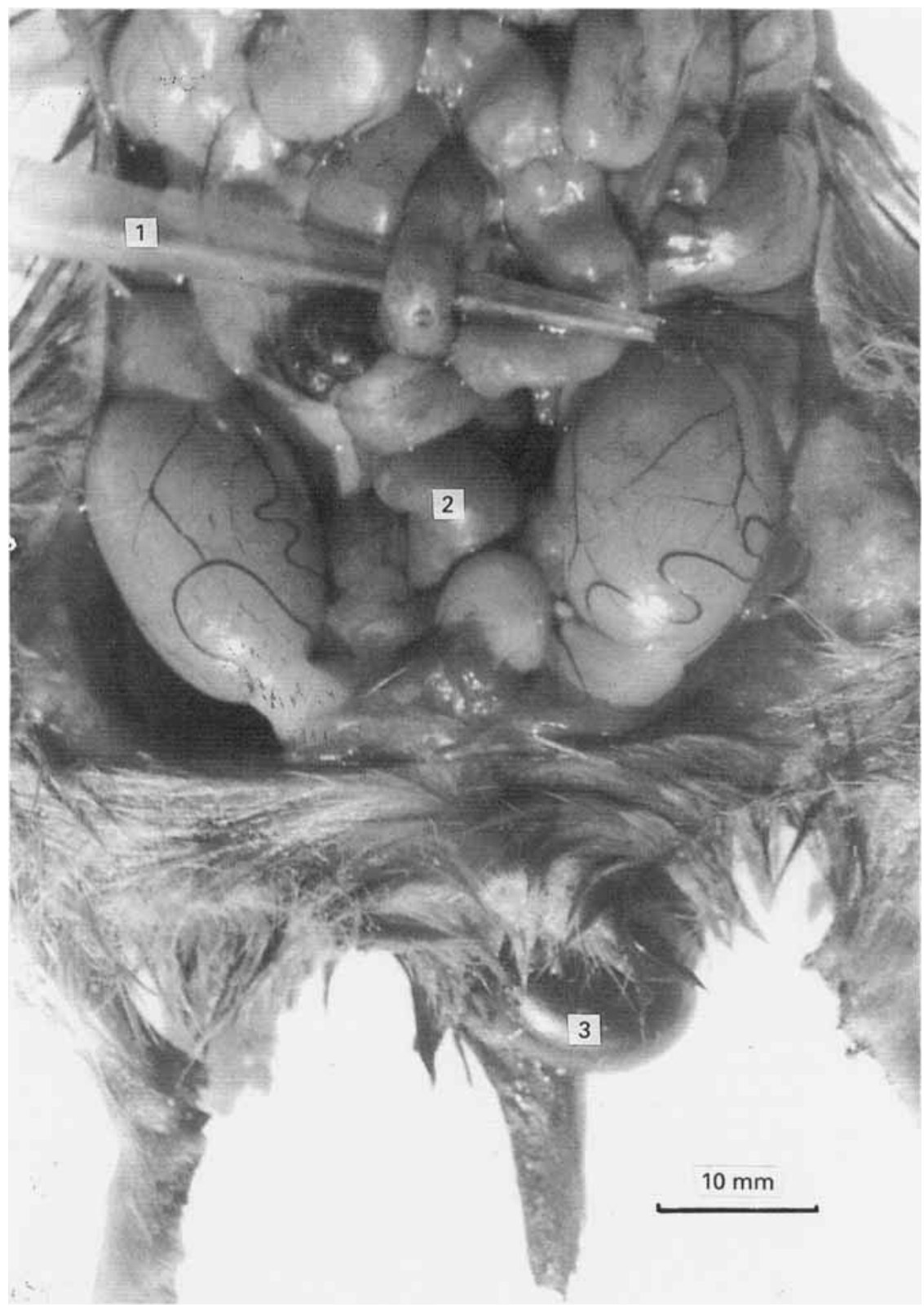




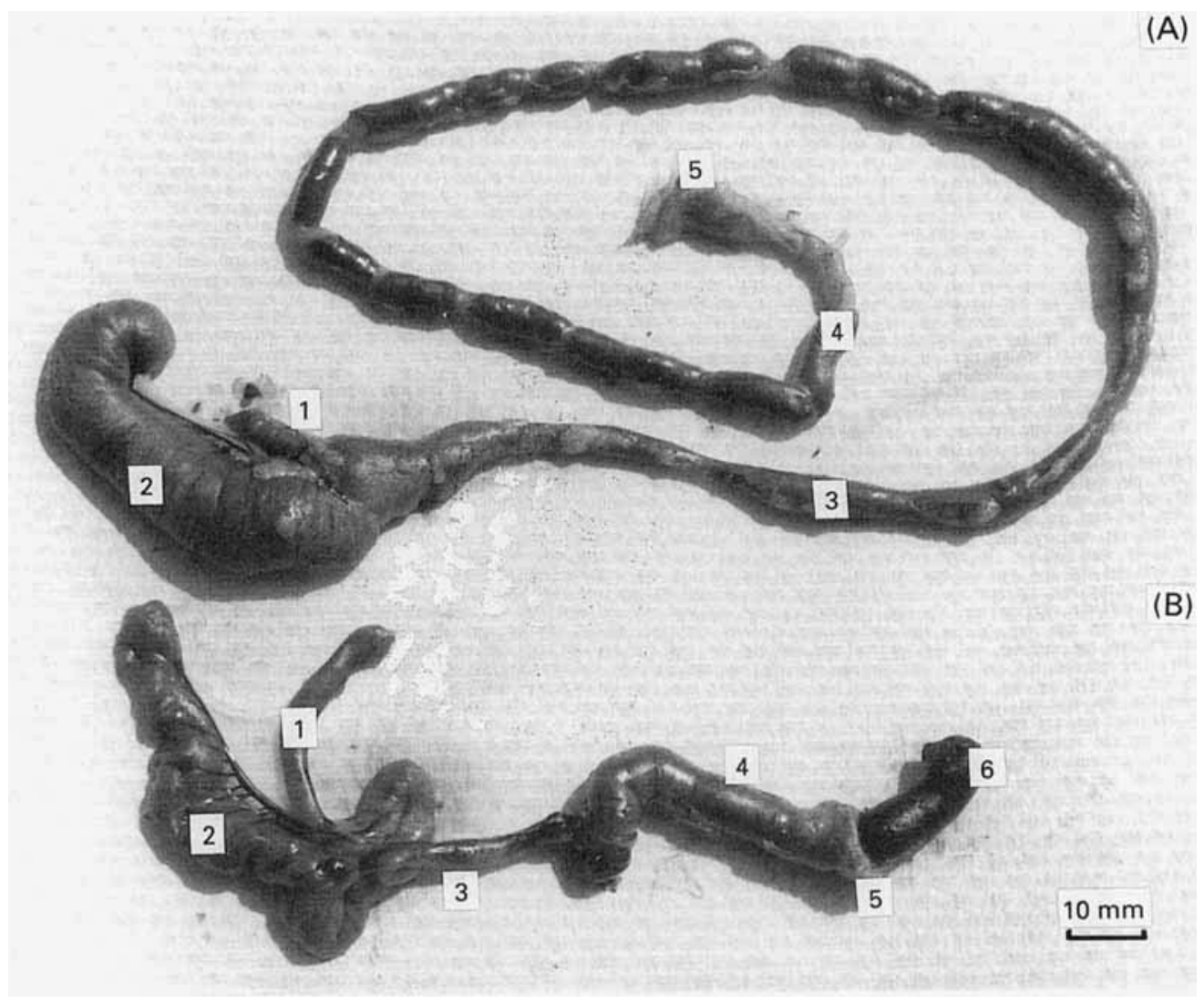


British Journal of Nutrition, Vol. 63 No. 2

Plate $3(\mathrm{~A}, \mathrm{~B})$

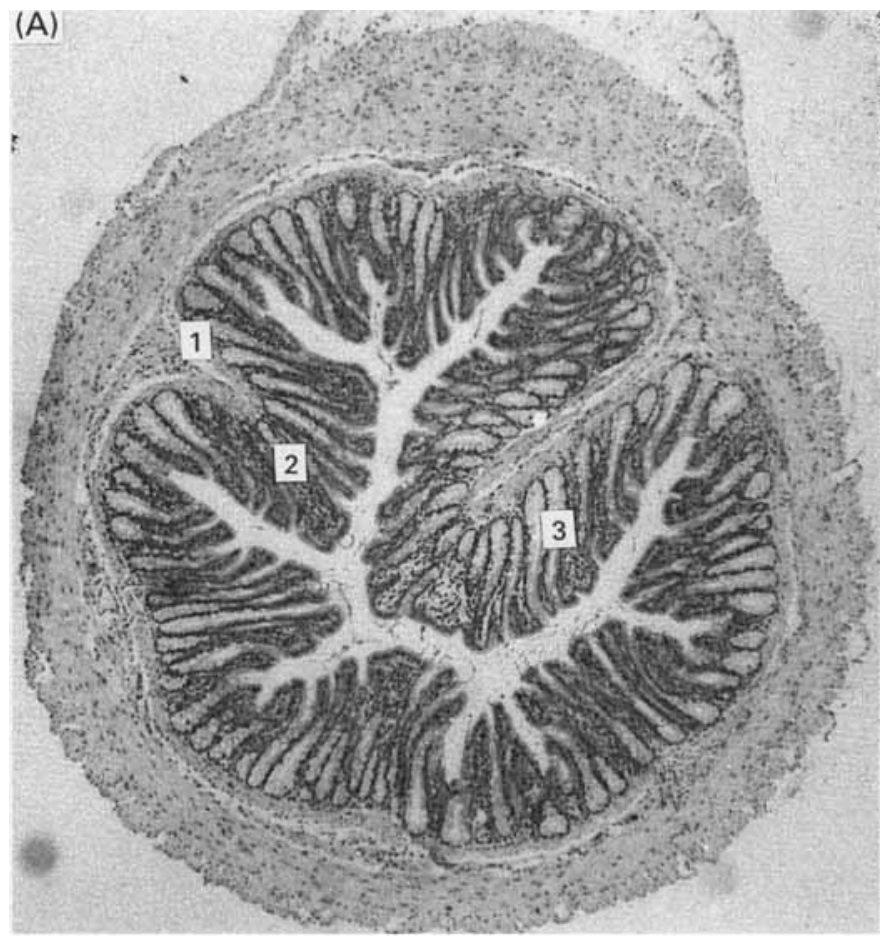

(B)

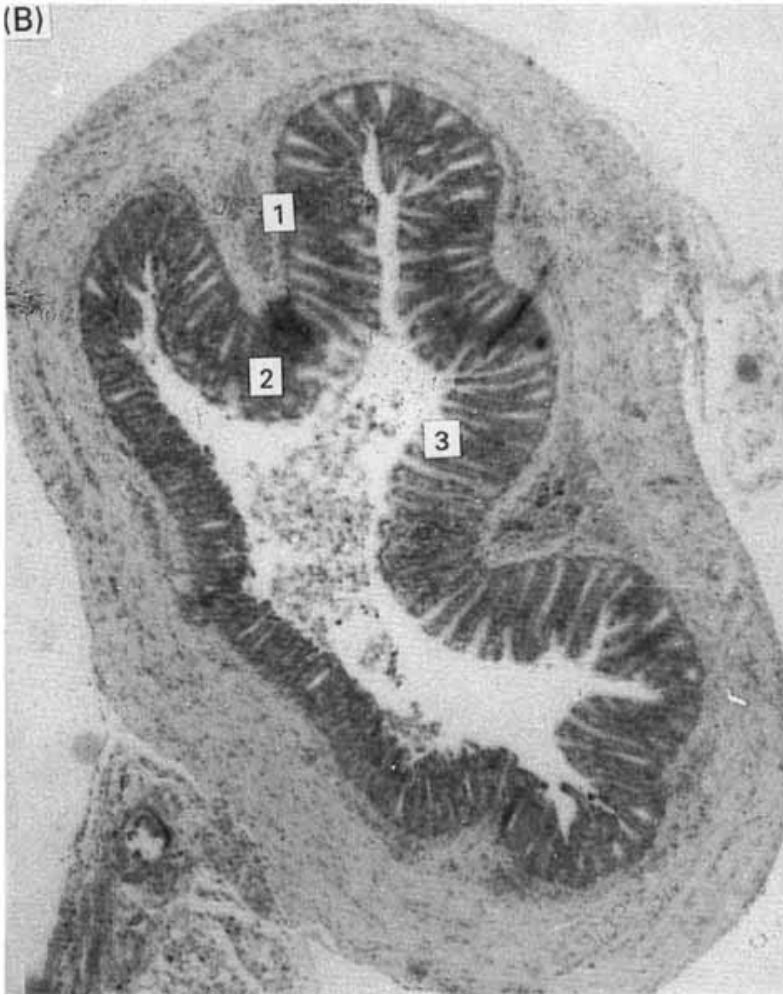




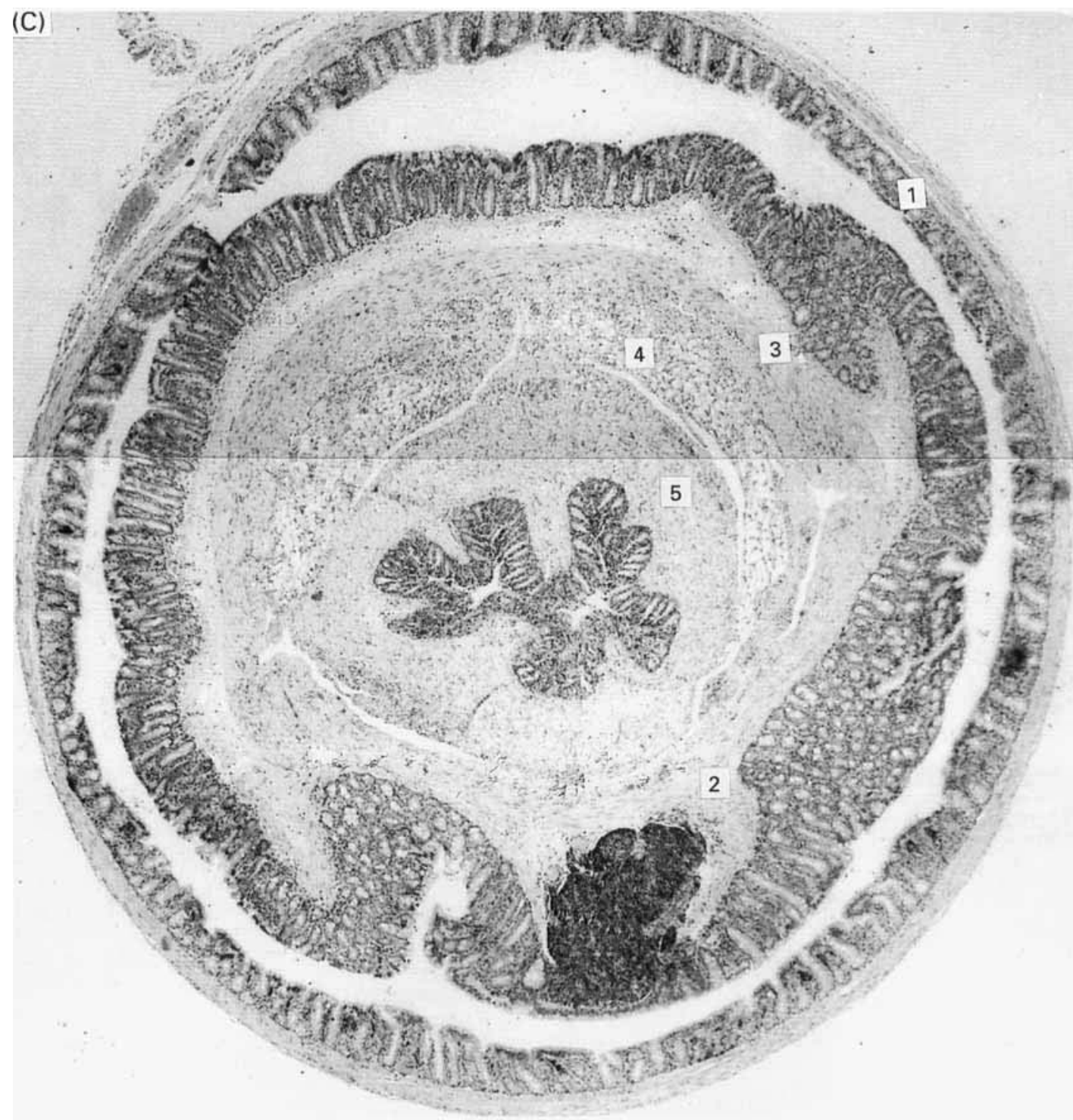


British Journal of Nutrition, Vol. 63, No. 2

Plate 4
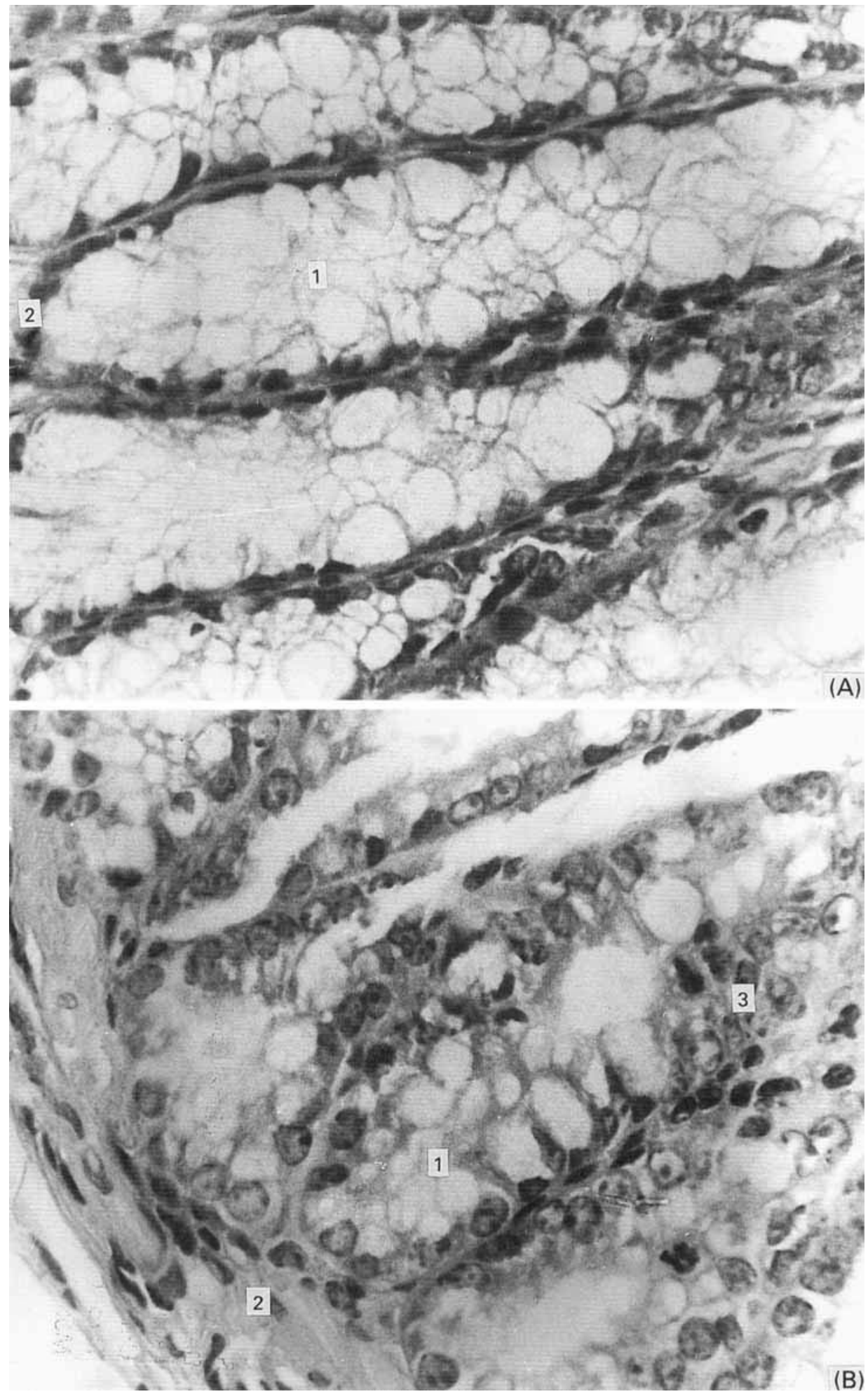

S. C. Cunnane AND others 


\section{EXPLANATION OF PLATES}

Plate 1. View of the abdominal organs of a hamster with intussusception. The pipette tip (1) is under the colon immediately proximal to the intussusception (2). The intussuscepted colon is prolapsed through the anus (3).

Plate 2. Dissected terminal ileum (1), caecum (2), colon (3), rectum (4) and anus (5) from a healthy hamster (A) and from a hamster with intussusception (B). The full length of the rectum is intact in $B$ and the intussuscepted colon is prolapsed through the anus (6). Only $70 \mathrm{~mm}$ of the original $250 \mathrm{~mm}$ of colon remain intact in B.

Plate 3. Cross-sections through the colon of a healthy hamster (A), through the colon just proximal to (B), and through the rectum-colon in an intussusception (C). Tissue was preserved in formalin, embedded in paraffin and stained with haematoxylin-eosin. In the specimen from the healthy hamster, the mucosa (3) is high, mucus (2) production is prominent and the muscularis mucosae (1) is well-developed. In specimen $\mathrm{B}$, the mucosa is lower and the crypts contain little mucus. The muscularis mucosae is thinner than in $\mathrm{A}$. In $\mathrm{C}$, the outer layer (intussuscipiens) is the rectum (I). The entire inner core (intussusceptum) is composed of a reversed layer of colon (mucosa out and serosa (2) in) (3), mesenteric fat (4) and an inner layer of colon (5). Magnification on all three specimens is $\times 40$.

Plate 4. Cross-section through the mucosal crypts (1) of the colon from a healthy hamster (A) and immediately proximal to an intussusception (B). Tissue was preserved in formalin, embedded in paraffin and stained with haematoxylin-eosin. The sub-mucosa (2) is on the left in both specimens. The mucosal crypts (1) in the healthy hamster are full of mucus. In $\mathrm{B}$, the mucosal crypts (1) are lacking in mucus and contain infiltrated polymorphonuclear leucocytes (3). Magnification in both is $\times 1000$. 